\title{
Avaliação da atividade anti-inflamatória de própolis de abelha Apis mellifera: uma
}

\section{revisão}

\author{
Evaluation of anti-inflammatory activity of propolis from Apis mellifera: a review \\ Evaluación de la actividad antiinflamatoria del propóleo de abeja Apis mellifera: una revisión
}

Fernanda Baldomir da Cruz

ORCID: https://orcid.org/0000-0003-2699-9388

Faculdade de Ciências da Saúde, Brasil

Universidade de Brasília, Brasil

E-mail: f.baldomir@hotmail.com

Juliana de Freitas Ferreira

ORCID: https://orcid.org/0000-0001-8727-0043 Faculdade de Ciências da Saúde, Brasil Universidade de Brasília, Brasil E-mail: julianafferreiraunb@gmail.com

Dâmaris Silveira

ORCID: https://orcid.org/0000-0003-1851-5224 Faculdade de Ciências da Saúde, Brasil Universidade de Brasília, Brasil E-mail: damaris@unb.br

Yris Maria Fonseca-Bazzo

ORCID: https://orcid.org/0000-0002-1230-3207 Faculdade de Ciências da Saúde, Brasil Universidade de Brasília, Brasil E-mail: yrisfonseca@unb.br

\begin{abstract}
Resumo
A própolis é um material recolhido de fontes vegetais pelas abelhas, sendo usada para promover um ambiente asséptico na colmeia, embalsamar invasores, reparar frestas, além de promover manutenção de parâmetros ambientais, como temperatura e umidade. Possui várias atividades biológicas reconhecidas, tanto no meio popular quanto no científico, a citar: antioxidante, antimicrobiana, cicatrizante, anestésica, anti-inflamatória, dentre outras. Existem diversos tipos de própolis, a depender de fatores ambientais (tipo de vegetação visitada pelos insetos, clima ou estação do ano), além de fatores relacionados às próprias abelhas. Sua composição química é muito variada, sendo o grupo mais importante o dos flavonoides. O objetivo desse trabalho foi realizar uma revisão bibliográfica, a fim de investigar a atividade anti-inflamatória que já vinha sendo atribuída a própolis há séculos. A busca por artigos e teses em português, inglês e espanhol, publicados nos últimos 10 anos, foi realizada nas seguintes bases de dados: SciELO, Google Acadêmico, PubMed, MEDLINE, Catálogo de Dissertações e Teses da CAPES, BVS, CRD, Embase, Science Direct, Scopus e Cochrane Library. Os artigos obtidos ao final da pesquisa trouxeram diversos experimentos, in vivo e in vitro, utilizando própolis dos mais diversos tipos, coletadas em regiões e países diferentes. Os resultados foram muito favoráveis em relação aos extratos de própolis, que conseguiram atingir valores potenciais nos testes antiinflamatórios, principalmente quando comparados com substâncias isoladas já reconhecidas como bons antiinflamatórios. Ainda, muitos trabalhos trouxeram informações sobre os possíveis mecanismos moleculares da própolis, como inibição de enzimas específicas, bem como da produção de mediadores inflamatórios.
\end{abstract}

Palavras-chave: Própolis; Anti-inflamatório; Apis mellifera.

\begin{abstract}
Propolis is a material collected from plants by bees, used to promote an aseptic environment in the hive, embalming invaders and repairing cracks. It has several recognized biological activities, both in popular and scientific circles: antioxidant, antimicrobial, healing, anesthetic, anti-inflammatory, among others. There are several types of propolis, depending on environmental factors (type of vegetation visited by insects, climate, season) and factors related to the bees themselves. Its chemical composition is very extensive, the most important group being that of flavonoids. This work aimed to carry out a bibliographic review to investigate the anti-inflammatory activity attributed to propolis for centuries. The search for articles and theses in Portuguese, English and Spanish, published in the last 10 years, was carried out in the following databases: SciELO, Google Scholar, PubMed, MEDLINE, CAPES Catalog of Dissertations and Theses, BVS, CRD, Embase, Science Direct, Scopus and Cochrane Library. The articles obtained at the end of the research brought several experiments, in vivo and in vitro, using propolis of the most diverse types, collected in different regions and countries. The results were very favorable in relation to the propolis extracts, which
\end{abstract}


managed to reach potential values in anti-inflammatory tests, especially when compared with isolated substances already recognized as good anti-inflammatory. Still, many studies have brought information about the possible molecular mechanisms of propolis, such as inhibition of production of inflammatory mediators and specific enzymes.

Keywords: Propolis; Anti-inflammatory; Apis mellifera.

\section{Resumen}

El propóleo es un material recolectado de fuentes vegetales por las abejas, siendo utilizado para promover un ambiente aséptico en la colmena, embalsamar invasores, reparar grietas, además de promover el mantenimiento de parámetros como la temperatura y la humedad. Posee varias actividades biológicas reconocidas, tanto en círculos populares como científicos, entre ellas: antioxidante, antimicrobiana, cicatrizante, anestésica, antiinflamatoria, entre otras. Existen varios tipos de propóleos, en función de factores ambientales (tipo de vegetación que visitan los insectos, clima, temporada), además de factores propios de las abejas. Su composición química es extensa, siendo el grupo más importante los flavonoides. El objetivo de este trabajo fue realizar una revisión de la literatura para investigar la actividad antiinflamatoria atribuida al propóleo durante siglos. La búsqueda de artículos y tesis en portugués, inglés y español, publicados en los últimos 10 años, se realizó en las siguientes bases de datos: SciELO, Google Académico, PubMed, MEDLINE, Catálogo de Disertaciones y Tesis CAPES, BVS, CRD, Embase, Science Direct, Scopus y Cochrane Library. Los artículos obtenidos al final de la investigación trajeron varios experimentos, in vivo y in vitro, utilizando propóleos de los más diversos tipos, recolectados en diferentes regiones y países. Los resultados fueron muy favorables en relación a los extractos de propóleo, que lograron alcanzar valores potenciales en las pruebas antiinflamatorias, especialmente si se comparan con sustancias aisladas ya reconocidas como buenos antiinflamatorios. Muchos trabajos aportaron información sobre los posibles mecanismos moleculares del propóleo, como la inhibición de enzimas específicas, así como la producción de mediadores inflamatorios.

Palabras clave: Propóleo; Antiinflamatorio; Apis mellifera.

\section{Introdução}

A própolis pode ser definida como uma resina balsâmica complexa produzida pelas abelhas, a partir de exsudatos, coletados pelos insetos, de brotos e botões florais, por exemplo. O processo se inicia com a coleta das resinas vegetais pelos insetos, por meio de suas mandíbulas, e posterior transporte até a colmeia, utilizando a parte posterior da tíbia, chamada corbícula. No ninho, as abelhas acrescentam a esse material enzimas glandulares, como a $\beta$-13-glicosidase, cera e ácidos graxos-poliinsatudaros (Lungareze, 2010; Lima, 2012; Silva, 2012; Silva, Rodrigues, Feás \& Estevinho, 2012; Búfalo, 2013; Falcão, 2013; El-Guendouz, et al., 2016; Salas, et al., 2016; Tiveron, et al., 2016; Banzato, 2018; Núñez, et al., 2018; Falcão, et al., 2019; Oliveira, 2020; Boeing, et al., 2021). Tais enzimas adicionadas têm como função a quebra de glicosídeos a agliconas (por exemplo, flavonas e flavanonas) (Alves, 2018).

A coloração e o odor da própolis variam imensamente, indo de marrom a vermelho, passando pelo verde. Quanto às suas características físico-químicas, é uma substância lipofílica, com variações na textura de acordo com a temperatura: quanto mais alta a temperatura, mais maleável o material se torna. Na colmeia, tem como função a manutenção de parâmetros ambientais (umidade e temperatura), proteção contra crescimento microbiano; além disso, possui função estrutural, fechando frestas e estreitando a entrada da colmeia, a fim de impedir a entrada de insetos invasores. Porém, quando há a invasão e o animal é morto, sem a possibilidade de retirada de seu corpo do interior do ninho, as abelhas utilizam esse material resinoso para embalsamá-lo, evitando sua putrefação (Lungareze, 2010; Lima, 2012; Sartori, et al., 2012; Silva, 2012; Búfalo, 2013; Banzato, 2018; Núñez, et al., 2018; Falcão, et al., 2019; Oliveira, 2020; Boeing, et al., 2021).

Com relação as espécies de abelhas produtoras de própolis, podem ser citadas as pertencentes ao gênero Melipona, abelhas sem ferrão, encontradas em regiões de clima tropical como o Brasil. Tem como diferencial o acréscimo de terra à sua própolis, gerando a chamada geoprópolis (Dutra, Nogueira, Marques, Costa \& Ribeiro, 2008). Ainda, existem as abelhas do gênero Apis. Dentro desse grupo, destaca-se a espécie Apis mellifera, presente em todos os continentes do planeta, excluindose os polos. É conhecida como a mais eficiente produtora de própolis dentre todas as abelhas. Estima-se que há o potencial de extração de cerca de 100 a 300 gramas de própolis anualmente de cada colmeia de A. mellifera (Falcão, 2013). Devido ao exposto, a própolis de Apis mellifera foi escolhida como alvo da presente revisão bibliográfica. 
Existe uma classificação para os tipos de própolis existentes, baseada na origem botânica, coloração e composição química. Em climas temperados, há a predominância de árvore de álamo (Populus L.) como a principal fonte de busca dos insetos. Essa própolis, chamada poplar, é rica em flavonoides e ésteres do ácido cafeico. Em países de clima tropical, como o Brasil, pode ser encontrada uma maior variedade de plantas que servem como fonte para as abelhas, o que torna difícil a identificação da origem botânica (Lungareze, 2010; Búfalo, 2013; Banzato, 2018). A chamada própolis verde é extensamente estudada, tendo como matéria prima o alecrim-do-campo (Baccharis dracunculifolia), enquanto a vermelha foi descoberta no nordeste do Brasil, embora já fosse observada em áreas de Cuba e Venezuela. Sua provável origem botânica inclui Rizophora mangle, Schinus terebentifolius e Dalbergia ecastophyllum L. (Lungareze, 2010; Lima, 2012; Machado, et al., 2012; Banzato, 2018; Oliveira, 2020; Boeing, et al., 2021). Todos esses tipos de própolis referem-se a própolis produzida pela abelha da espécie Apis mellifera.

Podem ser encontrados no mercado diversos produtos que possuem em sua composição a própolis, tais como cápsulas, pós, xaropes, enxaguantes bucais, sabonetes, cremes, pomadas, dentifrícios e cosméticos (Jansen, 2015). Somente no Brasil, são produzidas cerca de 150 toneladas anualmente, dos quais 75\% seguem para exportação, especialmente para países asiáticos. No Japão, um frasco de própolis verde chega a custar até 150 dólares. Estima-se que o mercado brasileiro de própolis seja avaliado em 360 milhões de dólares (Adelman, 2005; Cavalaro, 2017; Ferreira, 2017)

Dentre as atividades atribuídas a própolis, podem ser citadas antioxidante, antimicrobiana, anti-cariogênica, antiinflamatória, citotóxica, antiviral, imunomodulatória, antineoplásica, anti-HIV, anti-ulcerogênica, e hepatoprotetora, resultando em um amplo uso para esse produto na indústria farmacêutica, alimentícia e cosmética (Lima, 2012; Machado, et al., 2012; Sartori, et al., 2012; Silva, 2012; Silva, Rodrigues, Feás \& Estevinho, 2012; Búfalo, 2013; El-Guendouz, et al., 2016; Salas, et al., 2016; Tiveron, et al., 2016; Banzato, 2018; Núñez, et al., 2018; Falcão, et al., 2019; Oliveira, 2020; Boeing, et al., 2021).

As diversas atividades farmacológicas podem ser explicadas pela sua grande diversidade de composição química, formada por cerca de 50-60\% de resinas, 30-40\% de ceras, 5-10\% de óleos essenciais e 5\% de pólen (Lungareze, 2010; Lima, 2012; Búfalo, 2013; El-Guendouz, et al., 2016; Banzato, 2018; Núñez, et al., 2018; Falcão, et al., 2019).

Dentre as mais de 300 substâncias que podem ser encontradas, estão ácidos fenólicos e seus ésteres, álcoois, cetonas e aldeídos fenólicos, bem como traços de vitaminas (complexo B, E e C) e microelementos (alumínio, cálcio, estrôncio, ferro, dentre outros) (Lungareze, 2010; Lima, 2012; Machado, et al., 2012; Silva, 2012; Búfalo, 2013; Banzato, 2018; Núñez, et al., 2018; Oliveira, 2020). Podem ser encontrados, ainda, outros metabólitos secundários vegetais na própolis. São chamados de metabólitos secundários moléculas produzidas pelas plantas a fim de responder a estímulos ambientais diversos, tais como ataque de patógenos ou de herbívoros. Dentre eles, destacam-se os compostos fenólicos, em especial os flavonoides, sendo estes os mais estudados. Também há a presença de terpenos, e outras classes de compostos. Um composto bastante descrito é a artepilina C, um ácido cinâmico com propriedades antimicrobianas, antitumorais e anti-inflamatórias, encontrado principalmente na própolis verde (Zeggio, 2016).

Sabe-se, porém, que cada tipo de própolis apresenta uma composição química e, consequentemente, variadas atividades biológicas. Isso se deve à diversidade intrínseca da origem vegetal, pois as plantas modificam seus metabólitos segundo fatores ambientais externos e sazonalidade. Soma-se a isso, ainda, características próprias da abelha, como a genética da rainha (Lungareze, 2010; Sartori, et al., 2012; El-Guendouz, et al., 2016; Salas, et al., 2016; Falcão, et al., 2019).

A atividade anti-inflamatória da própolis vem sendo descrita em vários trabalhos (Machado, et al., 2012; Núñez, et al., 2018). A própolis pode ser utilizada na forma de fitoterápico, a fim de aliviar processos inflamatórios, em especial, os relacionados com o sistema músculo-articular (Lungareze, 2010). Também há relatos e seu uso para o tratamento de problemas dermatológicos, cicatrização e queimaduras (Abreu, 2008). 
Pode-se chamar de resposta inflamatória o conjunto de processos do organismo estimulados por um dano (Búfalo, 2013; Núñez, et al., 2018), tanto celular quanto tecidual. É mediada por moléculas produzidas tanto pelas células lesadas quanto pelas células do sistema imune (macrófagos, neutrófilos, basófilos, dentre outros) que interagem na região lesionada. Como exemplo de moléculas pró-inflamatórias, podem ser citadas a histamina, bradicinina e prostaglandinas (Vianna, Soares, Tavares, Teixeira \& Silva, 2011; Silva, Rodrigues, Feás \& Estevinho, 2012; Bueno-Silva, et al., 2017). Caso haja ativação contínua do sistema imune ou a sua exacerbação, a saúde do organismo pode ser prejudicada, estando intimamente ligada com o surgimento e agravamento de diversas doenças, como a artrite, câncer e Alzheimer (Abreu, 2008; El-Guendouz, et al., 2016; Banzato, 2018).

Embora no mercado já existam fármacos anti-inflamatórios, como os glicocorticoides e os anti-inflamatórios não esteroidais (AINE), há urgência da descoberta de moléculas mais eficientes e com menor potencial de efeitos adversos (RuizHurtado et al., 2021). Assim, os pesquisadores voltam seus olhos para a natureza, em busca de substâncias capazes de aliviar o sofrimento humano (Núñez, et al., 2018).

De modo a contribuir com os estudos relativos à própolis da abelha Apis mellifera, o presente trabalho teve como objetivo investigar, por meio de uma revisão bibliográfica, as evidências da atividade anti-inflamatória de extratos da própolis, bem como associar os dados encontrados com a composição química desse produto natural.

\section{Metodologia}

Dentre as bases de dados para a busca dos materiais, foram escolhidas: SciELO (Scientific Electronic Library Online), Google Acadêmico, PubMed, MEDLINE (Medical Literature Analysis and Retrieval Sistem on-line), Catálogo de Dissertações e Teses da CAPES, CRD (Center of Review Dissemination), Embase, Cochrane Library, Scopus e Science Direct, com o objetivo de se garantir uma melhor abrangência sobre o tema.

Os critérios de inclusão foram artigos e teses escritos em português, inglês e espanhol, compreendidos entre os anos de 2010 a 2021, que focavam na avaliação, in vitro e in vivo, da atividade anti-inflamatória de extratos brutos de própolis da abelha Apis mellifera. Foram excluídos: (i) livros, artigos de opinião, artigos de revisão e banners de congresso; (ii) aqueles com restrição de linguagem e que não se enquadravam no período de tempo adequado; (iii) aqueles que não especificavam a espécie de abelha usada (Apis mellifera e suas subespécies); (iv) aqueles que descreviam experimentos usando extratos comerciais sem designação de como foram preparados; (iv) aqueles que usaram apenas extratos fracionados ou com purificação de substâncias; (v) aqueles que associavam o extrato de própolis a outras substâncias; (vi) aqueles que não informavam o local de coleta da própolis (região e país).

Tendo em vista as particularidades de cada base de dados, estratégias de busca dos artigos foram adaptadas para cada uma. Os termos de busca foram: "apis mellifera", "própolis," "atividade anti-inflamatória", bem como seus correspondentes em inglês. A busca final foi realizada com os seguintes termos observados no Quadro 1. 
Quadro 1. Descritores de busca adaptados para as necessidades de cada base de dados escolhida.

\begin{tabular}{|c|c|}
\hline Base de Dados & Descritor \\
\hline $\begin{array}{c}\text { Google Acadêmico } \\
\text { Catálogo de Dissertações e Teses } \\
\text { da CAPES } \\
\text { Scopus } \\
\text { Science Direct }\end{array}$ & $\begin{array}{l}\text { "apis mellifera" AND "propolis" AND "anti-inflammatory" } \\
\text { "apis mellifera" AND "própolis" AND "anti-inflamatório" }\end{array}$ \\
\hline PubMed & $\begin{array}{l}\text { ((apis mellifera) AND (propolis)) AND (anti-inflammatory) } \\
\text { ((apis mellifera) AND (própolis)) AND (anti-inflamatório) }\end{array}$ \\
\hline $\begin{array}{l}\text { SciELO } \\
\text { BVS }\end{array}$ & $\begin{array}{l}\text { (apis mellifera) AND (propolis) AND (anti-inflammatory) } \\
\text { (apis mellifera) AND (própolis) AND (anti-inflamatório) }\end{array}$ \\
\hline Cochrane Library & $\begin{array}{c}\text { apis mellifera in Title Abstract Keyword AND propolis in Title Abstract } \\
\text { Keyword AND anti-inflammatory in Title Abstract Keyword - (Word } \\
\text { variations have been searched) } \\
\text { apis mellifera in Title Abstract Keyword AND própolis in Title Abstract } \\
\text { Keyword AND anti-inflamatório in Title Abstract Keyword - (Word } \\
\text { variations have been searched) }\end{array}$ \\
\hline CRD & $\begin{array}{l}\text { (apis mellifera) AND (propolis):TI AND (anti-inflammatory):AU IN } \\
\text { DARE, NHSEED, HTA } \\
\text { (apis mellifera) AND (própolis):TI AND (anti-inflamatório):AU IN DARE, } \\
\text { NHSEED, HTA }\end{array}$ \\
\hline Embase & $\begin{array}{l}\text { 'apis mellifera' AND 'propolis' AND 'anti-inflammatory' } \\
\text { 'apis mellifera' AND 'própolis' AND 'anti-inflamatório' }\end{array}$ \\
\hline
\end{tabular}

Fonte: Autores.

\section{Resultados}

Com a pesquisa inicial dos buscadores, foi obtido um total de 2220 artigos, que foram importados para o EndNote® Foram retirados pelo programa 140 artigos duplicados. Dos 2080 materiais restantes, 1998 foram eliminados após análise do título e dos resumos, uma vez que foi percebido que não se enquadravam nos critérios pré-estabelecidos. Os 82 artigos remanescentes foram lidos em sua totalidade, sendo excluídos mais 54 itens, devido a desvios nos critérios. O acervo da presente revisão baseou-se nos dados obtidos de um total de 28 artigos científicos, teses e dissertações, que formam o campo analítico, como mostrado abaixo na Figura 1. 
Figura 1. Diagrama de fluxo de pesquisa de literatura e critérios de seleção dos trabalhos da presente revisão bibliográfica.

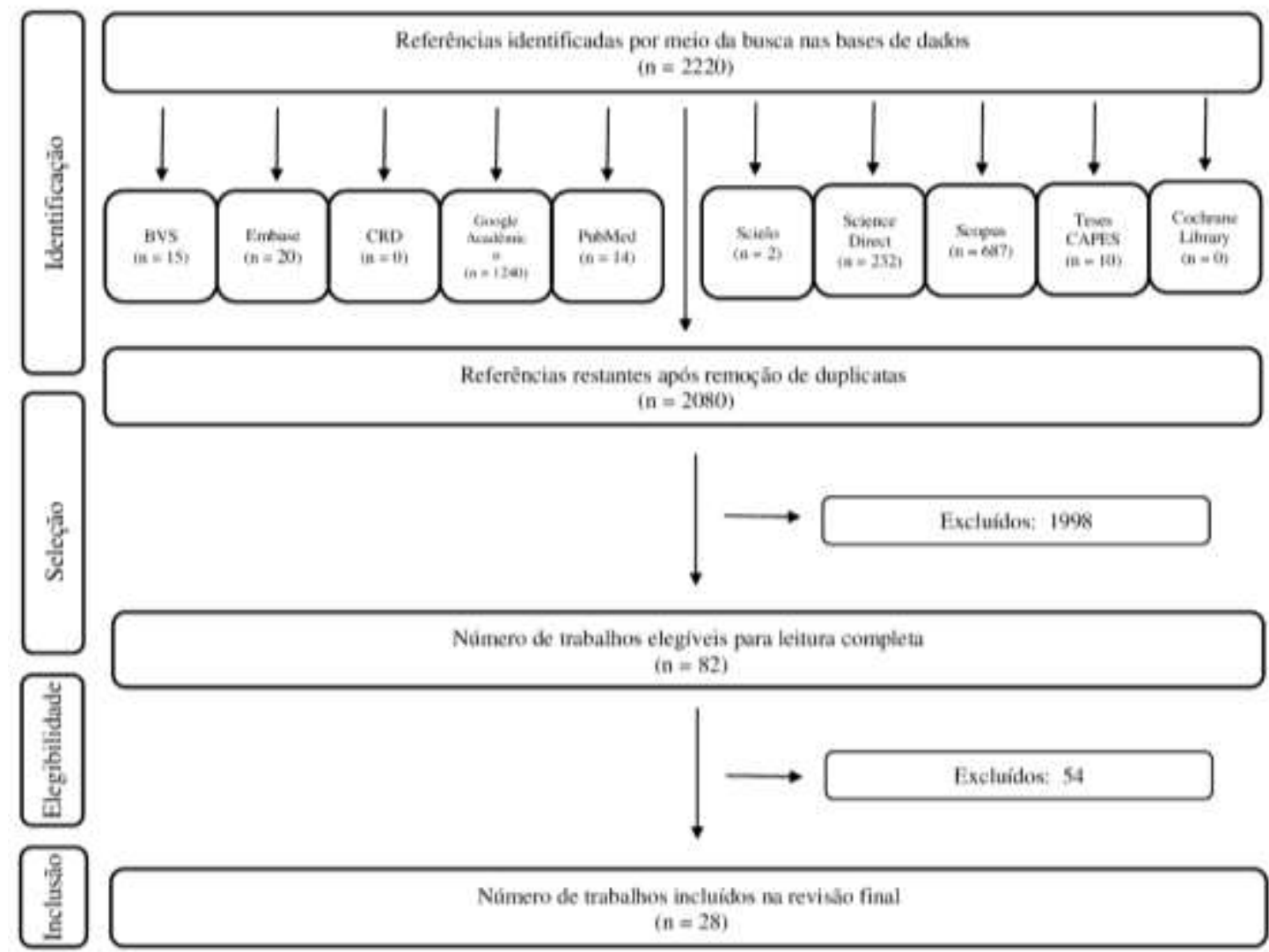

Fonte: Autores.

Os itens se referiram ao período de 2011 a 2021, com 23 artigos e 5 teses. Quanto ao idioma da publicação, 5 estavam escritos em português, 22 em inglês e 1 em espanhol. Apenas 18 itens tinham, de forma explícita, o tipo de própolis usada, e 26 deles traziam alguma informação de análises químicas do produto natural.

A grande maioria dos itens referiam-se a extratos etanólicos de própolis (EEP), embora alguns tenham, também, realizado testes com extrato aquoso (EAP), metanólico (EMP) e óleo essencial. É importante ressaltar que o extrato comercial mais comum é o etanólico (Búfalo, 2013). Além disso, os extratos etanólicos mostram ser melhores anti-inflamatórios quando comparados com os aquosos (Pacheco, 2001; Alencar, 2002). Isso pode ser explicado pela maior capacidade do etanol de extrair compostos bioativos diversos, tanto polares quanto apolares, em comparação com a água, considerando que possui características anfifílicas. Esse solvente tem a capacidade de extrair até $70 \%$ dos constituintes da própolis. As substâncias fenólicas extraídas por etanol são conhecidas como as responsáveis pelas ações atribuídas a esse produto natural (Lungareze, 2010; Machado, et al., 2012; Búfalo, 2013; Jug, Končić \& Kosalec, 2014). Ainda, etanol é um solvente que apresenta baixa toxicidade, e pode ser facilmente retirado das formulações, quando necessário (Gargouri, Osés, Fernández-Muiño, Sancho \& Kechaou, 2019). Seu ponto de ebulição mais alto $\left(78^{\circ} \mathrm{C}\right)$ permite extração com aquecimento, porém em temperatura mais branda, evitando a perda de compostos termossensíveis (Sousa, et al., 2019).

Quanto ao local de coleta da própolis, 15 trabalhos descreveram regiões brasileiras. A própolis brasileira é altamente requisita para exportação, principalmente em países asiáticos, como o Japão, devido a suas características de baixa quantidade de metais e outros contaminantes (Tiveron, et al., 2016), o que a torna adequada para as mais diversas pesquisas. Além disso, o 
Brasil é um país conhecido por possuir cerca de $20 \%$ de toda a biodiversidade vegetal do planeta (Oliveira, 2020), tendo, portanto, grande variedade de própolis produzidas.

As metodologias usadas variaram, com predomínio da avaliação da atividade inflamatória por meio de ensaios de doseamento de citocinas e fatores de transcrição (NF-kB), tanto in vivo quanto in vitro. Além disso, a atividade de algumas enzimas, como a mieloperoxidase (MPO) e a hialuronidase também foram utilizadas. Maiores informações sobre a metodologia dos trabalhos podem ser encontradas no Quadro 2, organizado de forma a mostrar a referência dos trabalhos dessa revisão bibliográfica e a descrição dos dados obrigatórios para serem aceitos nessa revisão, a saber, denominação exata da espécie de abelha usada, local de coleta (região e país) e metodologia de extração. Ainda, quando disponíveis, informações do tipo de própolis, época de coleta e provável fonte botânica também foram listados. Embora todos os trabalhos tenham trazido a espécie da abelha, nenhum deles especificou a existência de subespécies, como A. mellifera carnica ou A. mellifera scutellata.

O tipo de própolis escolhida foi citado em $64,28 \%$ dos trabalhos, sendo a mais popular a própolis vermelha $(32,89 \%)$, seguida por própolis poplar e verde $(22,22 \%$ cada), orgânica $(11,11 \%)$ e, por fim, a marrom $(5,56 \%)$. É chamada de própolis verde (tipo 12) aquela encontrada exclusivamente no Sudeste e Centro do Brasil, cuja espécie botânica principal de origem é Baccharis dracunculifolia (alecrim-do-campo). Como marcador principal, tem-se a molécula de artepilina C, um importante antioxidante, e ainda conta com derivados do ácido p-cumárico e diterpenos. É considerada uma das própolis mais estudadas no âmbito científico (Cavalaro, 2017; Quintino, et al., 2020).

A própolis vermelha (tipo 13) foi descrita no Brasil durante o ano de 2007, sendo amplamente estudada desde então. Tem como fonte botânica majoritariamente Dalbergia ecastapillum (rabo-de-bugio) e é encontrada nos mangues dos estados do Nordeste brasileiro, como Alagoas, bem como em países latinos (Cuba e México). É rica em isoflavonoides (Fianco, 2014; Rodrigues, Bueno-Silva \& Moraes, 2021). Em regiões temperadas, como na Europa, países da América do Norte e nos estados do Sul do Brasil, pode ser encontrada a própolis do tipo álamo (poplar). Tal denominação reflete a preferência das abelhas pelas árvores de álamo (Populus spp). Sua composição química é rica em flavonoides e ácidos fenólicos (Coelho, Falcão, Vale, Almeida-Muradian \& Vilas-Boas, 2017).

No que se refere a época de coleta das amostras no apiário, sabe-se que as abelhas teê preferência de coleta desse material resinoso nos períodos quentes do ano, como no verão, bem como nas horas mais quentes do dia. Isso se deve ao fato de que a própolis fica mais maleável e mais fácil de se manusear, bem como altas temperaturas volatilizam os compostos, atraindo as abelhas. Nos períodos frios, existe menos matéria prima disponível para a produção da própolis; inclusive, alguns autores afirmam que é melhor que se evite a coleta dessa resina balsâmica em tais épocas, a fim de não causar dano as colmeias (Pandolfo, 2014; Ferreira, 2019). Dentre os autores que optaram por informar a época de coleta por estação do ano, o verão e a primavera foram os mais citados.

Quadro 2. Detalhes das metodologias dos trabalhos que compõe o acervo da presente revisão bibliográfica.

\begin{tabular}{|l|l|l|l|l|l|l|}
\hline Referência & Abelha & Própolis & Local & Época & Origem & Extração \\
\hline $\begin{array}{l}\text { Núñez, et al., } \\
2018\end{array}$ & Apis mellifera & - & Bio-Bío (Chile) & - & - & $\begin{array}{l}\text { EEP (3:10) Etanol } \\
\text { absoluto Maceração - } \\
7 \text { dias }\end{array}$ \\
\hline $\begin{array}{l}\text { Salas, et al., } \\
2016\end{array}$ & Apis mellifera L. & - & $\begin{array}{l}\text { Tucumán } \\
\text { (Argentina) }\end{array}$ & $\begin{array}{l}\text { Dezembro } \\
(2012) \mathrm{e} \\
\text { Março (2013) }\end{array}$ & - & $\begin{array}{l}\text { EEP (2:25) Etanol } \\
80 \% \text { Maceração - 7 } \\
\text { dias }\end{array}$ \\
\hline $\begin{array}{l}\text { El-Guendouz, } \\
\text { et al., 2016 }\end{array}$ & Apis mellifera & - & Diversas regiões do & - & $\begin{array}{l}\text { EEP (1:30) Etanol } \\
70 \% \text { Maceração sob } \\
\text { agitação - 7 dias - } \\
37^{\circ} \mathrm{C}\end{array}$ \\
\hline
\end{tabular}




\begin{tabular}{|c|c|c|c|c|c|c|}
\hline $\begin{array}{l}\text { Falcão, et al., } \\
2019\end{array}$ & Apis mellifera $\mathrm{L}$. & Poplar & $\begin{array}{l}\text { Diversas regiões do } \\
\text { Marrocos }\end{array}$ & - & - & $\begin{array}{l}\text { EEP (1:10) Etanol } \\
80 \% \text { Agitação - } 1 \text { hora } \\
-70^{\circ} \mathrm{C}\end{array}$ \\
\hline $\begin{array}{l}\text { Tiveron, et al., } \\
2016\end{array}$ & Apis mellifera & Orgânica & $\begin{array}{l}\text { Santa Catarina } \\
\text { (Brasil) }\end{array}$ & $\begin{array}{l}\text { Fevereiro } \\
(2011) \text { a } \\
\text { Janeiro (2012) }\end{array}$ & - & $\begin{array}{l}\text { EEP (2:25) Etanol } \\
80 \% \text { Agitação - } 30 \\
\text { minutos }-70^{\circ} \mathrm{C}\end{array}$ \\
\hline Banzato, 2018 & Apis mellifera & Vermelha & Alagoas (Brasil) & Final do verão & $\begin{array}{l}\text { Dalbergia } \\
\text { odorifera }\end{array}$ & $\begin{array}{l}\text { EEP (2:25) Etanol } \\
80 \% \text { Agitação - } 30 \\
\text { minutos }-70^{\circ} \mathrm{C} \\
\end{array}$ \\
\hline Búfalo, 2013 & Apis mellifera $\mathrm{L}$. & - & São Paulo (Brasil) & - & - & $\begin{array}{l}\text { EEP (3:10) Etanol } \\
70 \% \text { Agitação - } 7 \text { dias }\end{array}$ \\
\hline Lima, 2012 & Apis mellifera & Verde & $\begin{array}{l}\text { Minas Gerais } \\
\text { (Brasil) }\end{array}$ & - & - & $\begin{array}{l}\text { EAP (2:5) Água } \\
\text { destilada Agitação - } 1 \\
\text { hora }-70^{\circ} \mathrm{C}\end{array}$ \\
\hline Oliveira, 2020 & Apis mellifera & Vermelha & Alagoas (Brasil) & - & $\begin{array}{l}\text { Dalbergia } \\
\text { ecastaphyllum }\end{array}$ & $\begin{array}{l}\text { EEP (2:25) Etanol } \\
70 \% \text { Ultrassom - } 1 \\
\text { hora }\end{array}$ \\
\hline Silva, 2012 & Apis mellifera & - & $\begin{array}{l}\text { Bragança, Coimbra } \\
\text { e Breja (Portugal) }\end{array}$ & $\begin{array}{l}\text { Outono } \\
(2010)\end{array}$ & - & $\begin{array}{l}\text { EAP }(1: 10) 80^{\circ} \mathrm{C} 3 \\
\text { horas EMP }(1: 10) \\
\text { Metanol } 80 \% 45^{\circ} \mathrm{C} 1 \\
\text { hora EEP }(1: 10) \\
\text { Etanol } 80 \% 45^{\circ} \mathrm{C} 1 \\
\text { hora }\end{array}$ \\
\hline $\begin{array}{l}\text { Boeing ,et al., } \\
2021\end{array}$ & Apis mellifera & Vermelha & Bahia (Brasil) & - & $\begin{array}{l}\text { Dalbergia } \\
\text { ecastaphyllum } \\
\text { e Symphonia } \\
\text { globulifera }\end{array}$ & $\begin{array}{l}\text { EEP (1:10) Etanol } \\
70 \% \text { Maceração } \\
\text { dinâmica }-30^{\circ} \mathrm{C}\end{array}$ \\
\hline $\begin{array}{l}\text { Sartori, et al., } \\
2012\end{array}$ & Apis mellifera $\mathrm{L}$. & Marrom & $\begin{array}{l}\text { Rio Grande do Sul } \\
\text { (Brasil) }\end{array}$ & $\begin{array}{l}\text { Janeiro e } \\
\text { Fevereiro }\end{array}$ & - & $\begin{array}{l}\text { EEP }(3: 10) \text { Etanol } \\
70 \% \text { Soxhlet }\end{array}$ \\
\hline $\begin{array}{l}\text { Machado, et } \\
\text { al., } 2012\end{array}$ & Apis mellifera & Verde & $\begin{array}{l}\text { Diversos estados do } \\
\text { Brasil }\end{array}$ & - & $\begin{array}{l}\text { Baccharis } \\
\text { dracunculifolia }\end{array}$ & EAP (Patente) \\
\hline $\begin{array}{l}\text { Bezerra, et al., } \\
2017\end{array}$ & Apis mellifera & Vermelha & Alagoas (Brasil) & Junho (2011) & $\begin{array}{l}\text { Dalbergia } \\
\text { ecastaphyllum }\end{array}$ & $\begin{array}{l}\text { EEP (2:25) Etanol } \\
70 \% \text { Ultrassom - } 1 \\
\text { hora }\end{array}$ \\
\hline $\begin{array}{l}\text { Bueno-Silva, } \\
\text { et al., } 2017\end{array}$ & Apis mellifera & Vermelha & Alagoas (Brasil) & - & - & EEP (1:8) Etanol 80\% \\
\hline $\begin{array}{l}\text { Ruiz-Hurtado, } \\
\text { et al., } 2021\end{array}$ & Apis mellifera $\mathrm{L}$. & - & $\begin{array}{l}\text { Chihuahua } \\
\text { (México) }\end{array}$ & $\begin{array}{l}\text { Novembro } \\
(2017)\end{array}$ & - & $\begin{array}{l}\text { EEP (3:10) Etanol } \\
70 \% \text { Maceração }\end{array}$ \\
\hline $\begin{array}{l}\text { Gargouri, } \\
\text { Osés, } \\
\text { Fernández- } \\
\text { Muiño, } \\
\text { Sancho \& } \\
\text { Kechaou, } \\
2019\end{array}$ & Apis mellifera $\mathrm{L}$. & - & $\begin{array}{l}\text { Diversas regiões da } \\
\text { Tunísia }\end{array}$ & - & - & $\begin{array}{l}\text { EEP (1:50) Etanol } \\
80 \% \text { Agitação - } 3 \\
\text { horas - } 40^{\circ} \mathrm{C} \text { EEP } \\
(1: 15) \text { Etanol } 80 \% \\
\text { Ultrassom - } 20 \\
\text { minutos }\end{array}$ \\
\hline $\begin{array}{l}\text { Cavendish, et } \\
\text { al., } 2015\end{array}$ & Apis mellifera & Vermelha & Sergipe (Brasil) & - & $\begin{array}{l}\text { Dalbergia } \\
\text { ecastophyllum }\end{array}$ & $\begin{array}{l}\text { EEP (2:25) Etanol } \\
70 \% \text { Ultrassom -1 } \\
\text { hora }\end{array}$ \\
\hline $\begin{array}{l}\text { Valenzuela- } \\
\text { Barra, et al., } \\
2015\end{array}$ & Apis mellifera & - & Santiago (Chile) & $\begin{array}{l}\text { Primavera } \\
(2011)\end{array}$ & - & $\begin{array}{l}\text { EEP (8:15) Maceração } \\
-70^{\circ} \mathrm{C}-30 \text { minutos }\end{array}$ \\
\hline $\begin{array}{l}\text { Wang, et al., } \\
2014\end{array}$ & Apis mellifera $\mathrm{L}$. & Poplar & Shandong (China) & Verão (2010) & Populus sp. & $\begin{array}{l}\text { EEP }(1: 10) \text { Etanol } \\
95 \% \text { Sonicador }-40{ }^{\circ} \mathrm{C} \\
-3 \text { horas }\end{array}$ \\
\hline $\begin{array}{l}\text { Bueno-Silva, } \\
\text { et al., } 2015\end{array}$ & Apis mellifera & Vermelha & Alagoas (Brasil) & - & - & EEP (1:8) Etanol 80\% \\
\hline $\begin{array}{l}\text { Miguel, } \\
\text { Doughmi, }\end{array}$ & Apis mellifera & - & $\begin{array}{l}\text { Diversas regiões do } \\
\text { Marrocos }\end{array}$ & - & - & $\begin{array}{l}\text { EEP (1:30) Etanol } \\
70 \% \text { Maceração sob }\end{array}$ \\
\hline
\end{tabular}




\begin{tabular}{|c|c|c|c|c|c|c|}
\hline $\begin{array}{l}\text { Aazza, } \\
\text { Antunes \& } \\
\text { Lyoussi, } 2014\end{array}$ & & & & & & $\begin{array}{l}\text { agitação - } 4 \text { dias - } \\
37^{\circ} \mathrm{C}\end{array}$ \\
\hline $\begin{array}{l}\text { Hori, } \\
\text { Zamboni, } \\
\text { Carrão, } \\
\text { Goldman \& } \\
\text { Berretta, } 2013\end{array}$ & Apis mellifera $\mathrm{L}$. & Verde & $\begin{array}{l}\text { Diversas regiões do } \\
\text { Brasil }\end{array}$ & - & $\begin{array}{l}\text { Baccharis } \\
\text { dracunculifolia }\end{array}$ & $\begin{array}{l}\text { EEP - Etanol } 70 \% \\
\text { Maceração dinâmica - } \\
3 \text { dias }\end{array}$ \\
\hline $\begin{array}{l}\text { Moura, et al., } \\
2011\end{array}$ & Apis mellifera & Verde & $\begin{array}{l}\text { Minais Gerais } \\
\text { (Brasil) }\end{array}$ & $\begin{array}{l}\text { Setembro } \\
(2005) \text { a } \\
\text { Setembro } \\
(2006)\end{array}$ & $\begin{array}{l}\text { Baccharis } \\
\text { dracunculifolia }\end{array}$ & $\begin{array}{l}\text { EAP (2:5) Água } \\
\text { destilada Agitação - } 1 \\
\text { hora }-70^{\circ} \mathrm{C}\end{array}$ \\
\hline $\begin{array}{l}\text { Naik, } \\
\text { Mujumdar \& } \\
\text { Vaidya, } 2013\end{array}$ & Apis mellifera $\mathrm{L}$. & - & Maharashtra (India) & Verão & - & $\begin{array}{l}\text { EEP (20 g, extraída } \\
\text { exaustivamente) Óleo } \\
\text { volátil - } \\
\text { Hidrodestilação (1:28) }\end{array}$ \\
\hline $\begin{array}{l}\text { Nani, et al., } \\
2019\end{array}$ & Apis mellifera & Orgânica & Paraná (Brasil) & $\begin{array}{l}\text { Junho a } \\
\text { Agosto (2016) }\end{array}$ & - & $\begin{array}{l}\operatorname{EEP}(4: 1) \text { Etanol } 70 \% \\
\text { Maceração }-70^{\circ} \mathrm{C}-30 \\
\text { minutos }\end{array}$ \\
\hline $\begin{array}{l}\text { Xuan, Yuan, } \\
\text { Chang, Liu \& } \\
\text { Hu, } 2019\end{array}$ & Apis mellifera $\mathrm{L}$. & Poplar & Shandong (China) & - & Poplar sp. & $\begin{array}{l}\text { EEP Etanol 95\% - } 24 \\
\text { horas }\end{array}$ \\
\hline $\begin{array}{l}\text { Zheng, et al., } \\
2018\end{array}$ & Apis mellifera $\mathrm{L}$. & Poplar & Zhejiang (China) & - & - & $\begin{array}{l}\text { EEP Etanol 95\% } \\
\text { Sonicador }-40^{\circ} \mathrm{C}-3 \\
\text { horas }\end{array}$ \\
\hline
\end{tabular}

Apis mellifera L.: Apis mellifera Linnaeus; EEP: Extrato etanólico de própolis; EAP: Extrato aquoso de própolis; EMP: Extrato metanólico de própolis. Fonte: Autores.

\section{Discussão}

Dentre as metodologias usadas, uma que se destaca é a avaliação da atividade anti-inflamatória por meio da indução de edema em ratos (in vivo). Essa metodologia inclui o edema induzido na orelha do rato, por meio de óleo de croton ou TPA (12-O-tetradecanoilforbol-13-acetato). Há a pesagem da orelha edemaciada e posterior comparação de seu peso com um controle negativo; ou, ainda, a orelha pode ser analisada como lâmina histológica. Pode-se, também, induzir edema na pata do rato, por meio de carragenina; nesse caso, há a medição de volume da pata antes e depois da aplicação da amostra. Essa metodologia tem a vantagem de demonstrar a resposta inflamatória sistêmica (Abreu, 2008).

Ainda, outro teste é a mensuração da atividade anti-inflamatória da própolis por meio da inibição da atividade da enzima hialuronidase. Essa enzima é uma das principais responsáveis pelas reações químicas que levam a formação de mediadores pró-inflamatórios, uma vez que a despolimerização do ácido hialurônico culmina em desgaste de cartilagem e do osso, iniciando processos inflamatórios. É, portanto, uma medida indireta (Alencar, 2002; Silva, Rodrigues, Feás \& Estevinho, 2012). Outra enzima extensamente estudada nos trabalhos dessa revisão foi a mieloperoxidase (MPO). É produzida por neutrófilos, e sua quantificação mostra-se proporcional a quantidade dessas células presentes nos tecidos inflamados, bem como sua ativação e quimiotaxia (Sartori, et al., 2012; Bezerra, et al., 2017; Banzato, 2018; Ruiz-Hurtado, et al., 2021.

A quantificação da produção de óxido nítrico (NO), ou da sua inibição, é outro importante teste, devido à capacidade sinalizadora dessa molécula, sendo capaz de modular processos como o tônus vasculares e a angiogênese. É sintetizado pela enzima óxido nítrico sintetase (NOS), com isoformas constitutivas e outra induzíveis (iNOS) (Bezerra, et al., 2017; BuenoSilva, et al., 2017).

Alguns trabalhos usaram metodologias que visavam a quantificação da inibição da migração de células imunes, como os neutrófilos. Ela é especialmente importante por que essa estratégia de combate a processos infeciosos mostra-se mais eficaz e com menos efeitos adversos. Por isso, muito se pesquisa no quesito de produção de citocinas e outras moléculas que 
impulsionem a migração de neutrófilos, como as proteínas de adesão (Nani, 2020). Os resultados obtidos pelos diferentes trabalhos analisados pela presente revisão bibliográfica estão demonstrados na Tabela 1.

Tabela 1. Atividade anti-inflamatória de extratos de própolis de A. mellifera, obtida por diferentes métodos de avaliação.

\begin{tabular}{|c|c|c|}
\hline Referência & Metodologia & Resultado \\
\hline Núñez, et al., 2018 & $\begin{array}{l}\text { Edema de orelha de rato induzido por TPA } \\
\text { (in vivo) }-100 \mu \mathrm{g} \text { de amostra/orelha }\end{array}$ & $\begin{array}{l}\text { Redução do diâmetro histológico de inflamação: } 0,22 \mathrm{~mm} \\
\text { (diferença de tamanho entre a orelha controle positivo - } \\
0,48 \mathrm{~mm} \text { - para inflamação e a orelha tratada com amostra - } \\
0,26 \mathrm{~mm} \text { ) }\end{array}$ \\
\hline Salas, et al., 2016 & $\begin{array}{l}\text { Inibição de enzimas inflamatórias: COX-2 e } \\
\mathrm{LOX} \text { (in vitro) - } 100 \mu \mathrm{g} / \mathrm{mL} \\
\text { Inibição da produção de óxido nítrico (NO) } \\
\text { (in vitro) }-12-50 \mu \mathrm{g} / \mathrm{mL}\end{array}$ & $\begin{array}{l}\mathrm{LOX}\left(\mathrm{CI}_{50}\right): 94,9 \mu \mathrm{g} / \mathrm{mL} \text { (dezembro) e } 63,9 \mu \mathrm{g} / \mathrm{mL} \text { (março) } \\
\text { COX-2 (CI50): 106,0 } \mu \mathrm{g} / \mathrm{mL} \text { (dezembro) e } 100,0 \mu \mathrm{g} / \mathrm{mL} \\
\text { (março) } \\
\text { NO (IC } \text { IC }_{50}: 8,4 \mu \mathrm{g} / \mathrm{mL} \text { (dezembro) e } 9,4 \mu \mathrm{g} / \mathrm{mL} \text { (março). } \\
\text { Houve diminuição da produção de iNOS }\end{array}$ \\
\hline $\begin{array}{l}\text { El-Guendouz, et al., } \\
2016\end{array}$ & $\begin{array}{l}\text { Inibição das enzimas LOX e hialuronidase } \\
\text { (in vitro) }-33,33 \mathrm{mg} / \mathrm{mL}\end{array}$ & $\begin{array}{l}\text { LOX }\left(\mathrm{CI}_{50}\right): 0,02-0,653 \mathrm{mg} / \mathrm{mL} \\
\text { Hialuronidase }(33,33 \mathrm{mg} / \mathrm{mL}):>80 \% \text { de inibição }\end{array}$ \\
\hline Falcão, et al., 2019 & $\begin{array}{l}\text { Inibição da produção de } \mathrm{NO} \text { (in vitro) - } 10 \\
\mathrm{mg} / \mathrm{mL}\end{array}$ & $\mathrm{NO}\left(\mathrm{CI}_{50}\right): 14-52 \mu \mathrm{g} / \mathrm{mL}$ \\
\hline Tiveron, et al., 2016 & $\begin{array}{l}\text { Quantificação da ativação de NF-kB e } \\
\text { liberação de TNF- } \alpha \text { por macrófagos (in } \\
\text { vitro) }-10 \mu \mathrm{g} / \mathrm{mL}\end{array}$ & $\begin{array}{l}\text { Houve diminuição dos níveis de ativação de NF-kB e } \\
\text { liberação de TNF- } \alpha \text {, além de diminuir MAPK p-p38 e } \\
\text { fosforilação de p-JNK }\end{array}$ \\
\hline
\end{tabular}

Edema de pata de rato induzido por carragenina, composto 48/80, bradicinina, prostaglandina (in vivo) $-200 \mathrm{mg} / \mathrm{kg}$

Banzato, 2018 Edema de orelha de rato induzido por óleo de crotón (in vivo) - $200 \mathrm{mg} / \mathrm{mL}$

Expressão da enzima MPO (in vivo) - 200 $\mathrm{mg} / \mathrm{mL}$

Búfalo, 2013

Quantificação de citocinas (in vitro) - $100 \mu \mathrm{g}$ Inibição de produção de NO e de vias específicas (in vitro) - $10 \mu \mathrm{g}$

Avaliação da inflamação induzida em ratos

Lima, 2012 pelo implante de esponja (in vivo) - 500 $\mathrm{mg} / \mathrm{kg}$ (4 dias)

Quantificação de IL-1 $\beta$ em camundongos induzidos em modelo convulsivo por pentilenotetrazol (PTZ) e pilocarpina (in vivo) - 10 e $100 \mathrm{mg} / \mathrm{kg}$

Lungareze, 2010

Inibição da enzima hialuronidase (in vitro) $25 \mathrm{mg} / \mathrm{mL}$

Silva, 2012

Boeing, et al., 2021 Inibição da MPO em ratos induzidos com úlcera gástrica (in vivo) - $300 \mathrm{mg} / \mathrm{kg}$ Atividade de MPO, contagem de células

Sartori, et al., 2012 imunes, e histopatologia em ratos infectados com vírus da herpes simples (in vivo) - 50 $\mathrm{mg} / \mathrm{kg}$

Avaliação da inflamação em ratos com granuloma de pelota de algodão, por meio de Machado, et al., 2012 contagem de células imunes no sangue e nos órgãos imunes, além de dosagem de citocinas (in vivo) $-5 \mathrm{mg} / \mathrm{kg}$ (6 dias) Avaliação de parâmetros em ratos com colite ulcerativa induzida (in vivo) - 10 e $100 \mathrm{mg}$ de amostra/kg
Houve diminuição da inflamação na pata: 61,93 - 67,51\%

Houve diminuição da inflamação na orelha: $53,95 \%$

MPO: 50,21\% de inibição da migração de neutrófilos

Houve inibição da produção de TNF- $\alpha$ e IL- 10. Houve diminuição da produção de NO quando comparado o controle $(13,9 \mu \mathrm{M})$ e a amostra $(5,5 \mu \mathrm{M})$, além da diminuição da via de NF-kB e MAPKs

Houve diminuição da inflamação, com menor resposta vascular, além de diminuição de $49 \%$ de TFG- $\beta 1$ e $38 \%$ de colágeno. Porém, houve aumento de TNF- $\alpha$ (136\%), MPO (79\%) e NAG (37\%)

Houve diminuição da produção de IL-1 $\beta$ quando comparado o controle de PTZ $(550,4)$ e a amostra em $10 \mathrm{mg} / \mathrm{kg}(550,4)$ e $100 \mathrm{mg} / \mathrm{kg}(276,8)$, bem como quando comparado o controle de pilocarpina $(429,7)$ e a amostra em $10 \mathrm{mg} / \mathrm{kg}(302,5) \mathrm{e}$ $100 \mathrm{mg} / \mathrm{kg}(313,8)$

Porcentagem de inibição: 75,79\% (Bragança), 70,48\% (Coimbra), 53,76\% (Beja)

Houve inibição da atividade da MPO em 49,49\%

A amostra diminuiu a atividade da enzima MPO e diminuiu a quantidade de células imunes no sangue (neutrófilos), quando comparados ao grupo controle infectado. As lâminas mostraram diminuição da inflamação

As amostras tiveram diferentes efeitos: sem modificação nos parâmetros, anti-inflamatório e pró-inflamatório

Houve redução da inflamação, dano histológico e produção de MPO e iNOS. 


\begin{tabular}{|c|c|c|}
\hline Bueno-Silva, et al., 2017 & $\begin{array}{l}\text { Produção de NO e citocinas (in vitro) - } 60 \\
\mu \mathrm{g} / \mathrm{mL}\end{array}$ & $\begin{array}{l}\text { Houve a redução da produção de NO, IL1 } \alpha \text {, IL1 } \beta \text {, IL4, MCP- } \\
\text { 1, IL10, IL12p40, IL12p70, IL6, IL13, GM-CSF, G-CSF, } \\
\text { RANTES, MIP-1 } \alpha \text {, MIP-1 } \beta \text { e KC. Não houve alteração nos } \\
\text { níveis de IL17, IL19 } \alpha, \text { TNF- } \alpha \text { e IFN- } \gamma\end{array}$ \\
\hline $\begin{array}{l}\text { Ruiz-Hurtado, et al., } \\
2021\end{array}$ & $\begin{array}{l}\text { Quantificação de citocinas e da enzima MPO } \\
\text { em ratos com úlcera gástrica induzidas por } \\
\text { indometacina (in vivo) - 50, } 150 \text { e } 300 \\
\mathrm{mg} / \mathrm{kg}\end{array}$ & $\begin{array}{l}\text { Houve redução de TNF- } \alpha(1304,480 ; 781,705 \text { e } \\
800,260 \text { pg/g) quando comparado com o controle }(1825,640 \\
\text { pg/g), bem como de IL-1 } \beta(329,940 ; 248,075 ; 15,700 \text { pg/g) e } \\
\text { IL-6 }(687,055 ; 430,265 \text { e } 398,745 \text { pg/g), cujos controles são } \\
291,640 \text { e } 420,340 \text { pg/g } \\
\text { Houve diminuição da atividade da MPO }(230,580 ; 67,805 \text { e } \\
63,190 \mathrm{UI} / \mathrm{g}), \text { quando comparada com o controle }(470,635 \\
\text { UI/g) }\end{array}$ \\
\hline $\begin{array}{l}\text { Gargouri, Osés, } \\
\text { Fernández-Muiño, } \\
\text { Sancho \& Kechaou, } \\
2019\end{array}$ & Inibição da enzima hialuronidase (in vitro) & $12,61 \%-28,46 \%$ \\
\hline Cavendish, et al., 2015 & $\begin{array}{l}\text { Avaliação do edema de pata de rato e } \\
\text { peritonite induzidos por carragenina (in vivo) } \\
-3,10 \text { e } 30 \mathrm{mg} / \mathrm{kg}\end{array}$ & $\begin{array}{l}\text { Não houve diminuição no edema de pata em } 3 \mathrm{mg} / \mathrm{kg} \text {, mas } \\
\text { sim nas doses de } 10 \mathrm{mg} / \mathrm{kg}(23,4 \%) \text { e } 30 \mathrm{mg} / \mathrm{kg}(46,7 \%) \text {. } \\
\text { Houve inibição da migração de neutrófilos nas três doses: } \\
23,0 ; 25,9 \text { e } 50,7 \%\end{array}$ \\
\hline $\begin{array}{l}\text { Valenzuela-Barra, et al., } \\
2015\end{array}$ & $\begin{array}{l}\text { Determinação da inflamação em orelha de } \\
\text { ratos por TPA e AA (in vivo) - } 3 \mathrm{mg} / \text { orelha } \\
\text { Inibição da produção de } \mathrm{NO} \text { (in vitro) - } \\
25,00 \mu \mathrm{g} / \mathrm{mL}\end{array}$ & $\begin{array}{l}\text { Efeito anti-inflamatório em AA: } 8 \text { e } 59 \% \\
\text { Efeito anti-inflamatório em TPA: } 50 \text { e } 55 \% \\
\text { Inibição de NO: } 73,2 \% \text { e } 35,5 \%\end{array}$ \\
\hline Wang, et al., 2014 & $\begin{array}{l}\text { Expressão de genes pró-inflamatórios e } \\
\text { inibição da produção de NO (in vitro) - } 5 \text { e } \\
10 \mu \mathrm{g} / \mathrm{mL} \text {. } \\
\text { Diminuição da inflamação em ratos com } \\
\text { injúria de intestino induzida por LPS (in } \\
\text { vivo) }-25 \text { e } 100 \mathrm{mg} / \mathrm{kg}\end{array}$ & $\begin{array}{l}\text { Houve diminuição da expressão de mRNA de IL-6, IL-10, } \\
\text { iNOS, COX-2 e MCP-1, bem como da ativação de NF-kB } \\
(37,1 \%) \text {. Anda, houve diminuição da produção de NO }(12,75 \\
\mu \mathrm{M}), \text { quando comparado com o controle }(46,7 \mu \mathrm{M}) \text {. Houve a } \\
\text { promoção de produção de IL-10 e TNF- } \alpha \\
\text { Nos ratos, houve diminuição de IL- } 6 \text {, IL-10, MCP-1, TNF- } \alpha \\
\text { e IL-12p70, mas houve aumento de IFN- } \gamma\end{array}$ \\
\hline Bueno-Silva, et al., 2015 & $\begin{array}{l}\text { Produção de NO, citocinas e análise de vias } \\
\text { inflamatórias (in vitro) - } 50 \mu \mathrm{g} / \mathrm{mL}\end{array}$ & $\begin{array}{l}\text { Houve redução da produção de NO (78\%), IL-12, GM-CSF, } \\
\text { IFN- } \gamma \text {, IL- } 1 \beta \text {, IL-10 e TGF- } \beta \text {. Houve leve aumento de TNF- } \alpha \\
\text { e IL- } 6 \text {. Houve diminuição da fosforilação de NF- } \kappa B \text {, C-FOS } \\
\text { e MAPK p } 42 / 44\end{array}$ \\
\hline $\begin{array}{l}\text { Miguel, Doughmi, } \\
\text { Aazza, Antunes \& } \\
\text { Lyoussi, } 2014\end{array}$ & Inibição da enzima LOX (in vitro) & $\mathrm{CI}_{50}: 2,521-0,149 \mathrm{mg} / \mathrm{mL}$ \\
\hline $\begin{array}{l}\text { Hori, Zamboni, Carrão, } \\
\text { Goldman \& Berretta, } \\
2013\end{array}$ & $\begin{array}{l}\text { Inibição da produção de citocinas e de } \\
\text { enzimas (in vitro) - } 30 \text { e } 100 \mu \mathrm{g} / \mathrm{mL}\end{array}$ & $\begin{array}{l}\text { Houve redução da secreção de IL- } 1 \beta \text {, além de redução da } \\
\text { ativação de caspases }\end{array}$ \\
\hline Moura, et al., 2011 & $\begin{array}{l}\text { Avaliação histológica de ratos com } \\
\text { inflamação induzida por implante de esponja } \\
\text { (in vivo) }-500 \mathrm{mg} / \mathrm{kg}\end{array}$ & $\begin{array}{l}\text { Houve diminuição da vascularização local, bem como de } \\
\text { infiltrado de células inflamatórias (fibroblastos) }\end{array}$ \\
\hline $\begin{array}{l}\text { Naik, Mujumdar \& } \\
\text { Vaidya, } 2013\end{array}$ & $\begin{array}{l}\text { Inibição da inflamação em orelhas de rato } \\
\text { induzida por TPA (in vivo) - 0,25; 0,5 e } 1 \\
\text { mg/orelha }\end{array}$ & $\begin{array}{l}\text { Inibição da inflamação na orelha: 16,11 - 33,98\% (EEP) e } \\
17,46 \text { - 39,13\% (Óleo essencial) }\end{array}$ \\
\hline Nani, et al., 2019 & $\begin{array}{l}\text { Avaliação de citocinas e vias (in vitro) - } 10 \\
\mu \mathrm{g} / \mathrm{mL} \\
\text { Avaliação da migração de células em ratos } \\
\text { com peritonite induzida por carragenina (in } \\
\text { vivo) }-10 \text { e } 30 \mathrm{mg} / \mathrm{kg}\end{array}$ & $\begin{array}{l}\text { Houve diminuição da ativação de NF- } \kappa B(78 \%) \text { e de } \\
\text { liberação de TNF- } \alpha(75 \%) \\
\text { Houve diminuição da migração de neutrófilos (52 e 64\%) }\end{array}$ \\
\hline $\begin{array}{l}\text { Xuan, Yuan, Chang, Liu } \\
\& \mathrm{Hu}, 2019\end{array}$ & $\begin{array}{l}\text { Avaliação de vias inflamatórias (in vitro) - } \\
6,25 ; 12,5 \text { e } 25 \mu \mathrm{g} / \mathrm{mL}\end{array}$ & $\begin{array}{l}\text { Houve diminuição da expressão de TLR4, p-JNK, p-ERK1/2 } \\
\text { e p-p38, além da redução translocação de NF-кB para o } \\
\text { núcleo e dos níveis de LC3-II. }\end{array}$ \\
\hline Zheng, et al., 2018 & $\begin{array}{l}\text { Avaliação de vias inflamatórias e citocinas } \\
\text { (in vitro) }\end{array}$ & Houve diminuição na produção de IL- $1 \beta$, IL-1 $\alpha$ e IL-18 \\
\hline
\end{tabular}


AA: Ácido Araquidônico; C-FOS: Protooncogene C-FOS; CI50: Concentração Inibitória média; COX-2: Cicloxigenase-2; EEP: Extrato Etanólico de Própolis; ERK: Extracellular Signal-regulated Kinases; G-CSF: Granulocyte colony-stimulating factor; GM-CSF: Granulocyte Macrophage Colony-Stimulating Factor; IFN: Interferon; IL: Interleucina; iNOS: Óxido Nítrico Sintetase Induzível; JNK: C-Jun N-terminal Kinase; KC: Keratinocytes-derived Chemokine; LC: Light Chain; LOX: Lipoxigenase; LPS: Lipopolissacarídeo; MAPK: Mitogen Activated Protein Kinases; MCP: Monocyte Chemoattractant Protein; MIP: Macrophage Inflammatory Proteins;MPO: Mieloperoxidase; mRNA: Micro Ribonucleic Acid; NAG: N-acetilglicosamina; NF-kB: Nuclear Factor Kappa B; NO: Óxido Nítrico; PTZ: Pentilenotetrazol; RANTES: Regulated upon Activation, Normal T-cell Expressed, and Secreted; TFG: Transforming growth fator; TLR: Toll Like Receptor; TNF- $\alpha$ : Human Tumor Necrosis Factor- $\alpha$; TPA: 12-O-tetradecanoilforbol-13-acetato; UI: Unidade Internacional. Fonte: Autores.

A presente revisão trouxe testes in vitro e in vivo que demonstraram o poder da própolis em impedir a liberação de diversos mediadores inflamatórios, como eicosanoides, histamina e leucotrienos. Alguns autores sugeriram que outro mecanismo possível de ação desse composto é a inibição da enzima cicloxigenase (COX) e lipoxigenase (LOX), pois são intrinsecamente ligadas ao processo inflamatório. Um exemplo de composto presente na própolis que age por esse mecanismo de ação é o flavonoide galangina (Lungareze, 2010; Sartori, et al., 2012; Silva, 2012; El-Guendouz, et al., 2016). Outro mecanismo possível de ação da própolis pode ser a inibição da quimiotaxia de polimorfonucleares (Banzato, 2018).

Dentre as diversas substâncias que compõem o arsenal químico da própolis, algumas já obtiveram a comprovação de sua atividade anti-inflamatória. Um dos mais estudados é o ester fenetila do ácido cafeico (CAPE), cujos mecanismos antiinflamatórios baseiam-se na inibição da liberação de ácido araquidônico das membranas (Lungareze, 2010; Sartori, et al.,

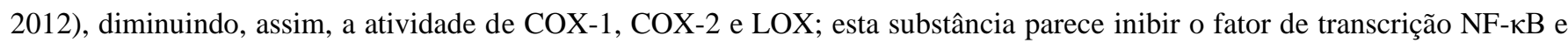
diminuir a produção de óxido nítrico. Além disso, CAPE é conhecida por suas propriedades antioxidantes (Lungareze, 2010; Silva, 2012; Búfalo, 2013; Valenzuela-Barra, et al., 2015; El-Guendouz, et al., 2016).

Outros compostos encontrados na própolis que possuem atividade anti-inflamatória são os flavonoides vestitol e neovestitol, com capacidade de diminuir a migração de neutrófilos, ao interferir com a Interleucina I- $\beta$, fator de transcrição NF- $\kappa$ B e outras quimiocinas (Cavendish, et al., 2015; Banzato, 2018). A isoflavona formononetina, por sua vez, age diminuindo os níveis de TNF- $\alpha$, IL-06, IL-1 $\beta$ e a produção de NO, bem como aumentando a atividade da enzima superóxido dismutase (Silva, 2012; Bezerra, et al., 2017; Bueno-Silva, et al., 2017; Banzato, 2018). Outro flavonoide com importante atividade anti-inflamatória é a quercetina. Seu mecanismo de ação está relacionado com vias de TLR4/ NF-אB (Búfalo, 2013), bem como a polarização de macrófagos e inibição da LOX e, consequentemente, da produção de leucotrienos e prostaglandinas (El-Guendouz, et al., 2016). A crisina consegue suprimir a enzima COX-2, diminuir a expressão de receptores PPAR- $\gamma$ e mRNA, de forma dose dependente, além de reduzir a produção de óxido nítrico (Silva, 2012; Valenzuela-Barra, et al., 2015; Ruiz-Hurtado, et al., 2021).

Alguns trabalhos sugeriram que a inibição da enzima hialuronidase está relacionada com a presença do ácido cinâmico e seus derivados, pois um fármaco disponível no mercado (Tranilast), produzido por modificações de derivados do ácido cinâmico, demonstrou ter uma potente atividade nos testes em questão (Ikegaki, 2001). Pode ser citada, ainda, a capacidade da artepilina C de diminuir a síntese de histaminas, prostaglandinas, NO e outras moléculas inflamatórias (Machado, et al., 2012; Búfalo, 2013).

Outros compostos fenólicos considerados importante para a ação anti-inflamatória da própolis são a naringenina, ácido cafeico, ácido felúrico, apigenina, ácido salicílico, kaempferol, ácido p-cumárico, pinocembrina, vanilina, ácido clorogênico, biochanina A, isoliquiritigenina, baicaleína e liquiritigenina (Lungareze, 2010; Valenzuela-Barra, et al., 2015; El-Guendouz, et al., 2016; Salas, et al., 2016; Bezerra, et al., 2017; Banzato, 2018; Oliveira, 2020; Ruiz-Hurtado, et al., 2021).

Em relação a capacidade anti-inflamatória dos flavonoides presentes na própolis, parece que há relação entre as duplas ligações nos carbonos $C_{2,3}$, grupos hidroxilas em 5,7,4' e grupo cetona na posição 4 (Figura 2), e a potência do efeito de 
inibição da enzima hialuronidase. Porém, deve-se ressaltar que a presença de grupos glicosídeos na molécula reduz essa inibição enzimática (Pacheco, 2001).

Figura 2. Esqueleto básico de flavonoides.

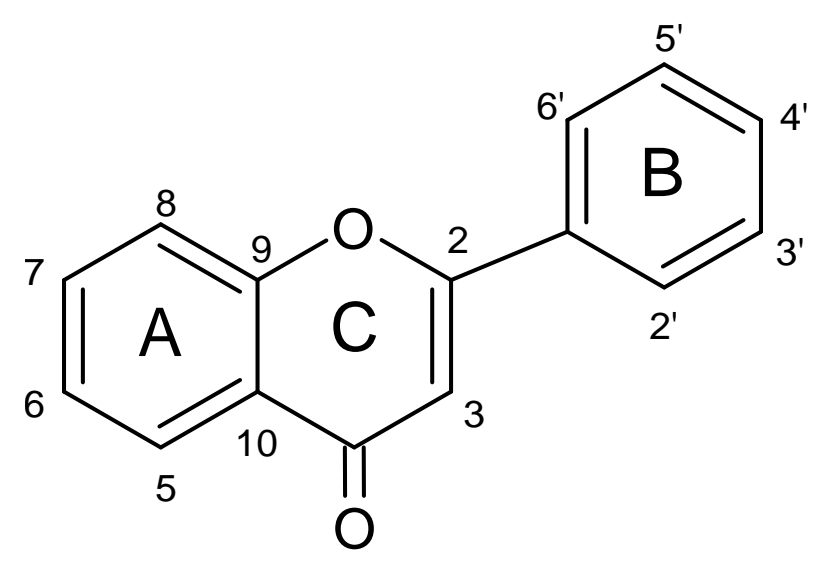

Fonte: Autores.

Alguns autores da presente revisão bibliográfica apoiaram a hipótese de que a atividade anti-inflamatória desse produto natural esteja ligada à presença de compostos fenólicos bioativos. Porém, outros autores não encontraram relação entre a quantidade de flavonoides totais e atividade biológica da própolis. Ainda, parece que atividades biológicas da própolis não é devida a um composto fenólico isolado, sendo também importantes as associações entre vários compostos fenólicos (Machado, et al., 2012) e entre esses e outras classes de compostos, como vitaminas e proteínas (Silva, 2012; El-Guendouz, et al., 2016; Núñez, et al., 2018; Falcão, et al., 2019; Gargouri, Osés, Fernández-Muiño, Sancho \& Kechaou, 2019).

Deve-se lembrar que, além dos mecanismos já descritos, a própolis ainda possui capacidade antioxidante (Machado, et al., 2012; Sartori, et al., 2012; Bezerra, et al., 2017), o que contribui para a atividade anti-inflamatória.

Em alguns dos estudos analisados, a própolis obteve eficácia semelhante, ou até mesmo maior, do que os controles positivos, como a dexametasona (Salas, et al., 2016; Bueno-Silva, et al., 2017; Banzato, 2018; Falcão, et al., 2019). A imensidão de resultados diferentes obtidos pode ser explicada pela constituição química heterogênea da própolis (Machado et al., 2012; Sartori, et al., 2012; Núñez, et al., 2018;), devido a fatores externos, como origem botânica, sazonalidade, métodos de coleta, extração e de testagem (Lima, 2012; Búfalo, 2013; Salas, et al., 2016; Oliveira, 2020). Dum estudo mostrou que abelhas colocadas em um mesmo apiário produziram própolis com constituições químicas diferentes, o que leva a supor que a planta ao qual aquele inseto visita deve estar intrínseca a seu código genético; abelhas semelhantes produzem o mesmo tipo de própolis mesmo em locais distintos (Ikegaki, 2001).

Tendo em vista os dados relatados, a própolis é um produto natural com amplo potencial de uso pela indústria farmacêutica e alimentícia, que gera impacto econômico. Rodrigues et al. (2021), realizaram uma busca de patentes dos últimos 20 anos em grandes bancos de dados relativos ao tema: European Patent Office (ESPACENET), World Intellectual Property Organization (WIPO), United States Patent and Trademark Office (USPTO) e no Instituto Nacional de Propriedade Intelectual (INPI). Os autores encontraram um total de 2823 patentes, demonstrando o interesse mundial por esse produto. Um dado interessante é que o Brasil encontra-se em quarto lugar dentre todos os países no quesito de registro de patentes, sendo superado apenas por países do extremo oriente (China, Coreia do Sul e Japão), os quais possuem grande interesse na própolis devido ao fato de utilizarem extensivamente as práticas integrativas e complementares de saúde. As patentes são depositadas, 
majoritariamente, para produtos para a saúde, seguidas pela indústria de alimentos e bebidas, bem como de cosméticos (Rodrigues, Bueno-Silva \& Moraes, 2021).

\section{Conclusão}

As atividades biológicas da própolis dependem da sua composição química, que varia enormemente de acordo com a vegetação que as abelhas escolhem para obter o material balsâmico. Por isso, os mecanismos e a potência anti-inflamatórias desse produto natural também diferem entre si; podem ser citados a inibição de enzima-chave para o processo inflamatório, como a cicloxigenase e lipoxigenase, inibição da atividade de moléculas pró-inflamatórias, como prostaglandinas e outras citocinas, inibição da migração de neutrófilos e outras células inflamatórias e redução da produção de fatores químicos, como $\mathrm{TNF}-\alpha$, a partir de vias metabólicas celulares.

Existem vários estudos na literatura que demonstram o grande potencial dos mais diversos tipos de própolis no controle da inflamação, inclusive, sendo comparadas aos controles positivos com fármacos já bem demarcados no meio clínico. Porém, nota-se divergência entre os resultados o que mostra a necessidade de mais estudos, principalmente clínicos, para aumentar as evidências da atividade anti-inflamatória, e químicos, no sentido de promover a padronização dos ensaios de análises de própolis, bem como definir marcadores de qualidade dessa.

\section{Agradecimentos}

Os autores agradecem ao Conselho Nacional de Desenvolvimento Científico e Tecnológico (CNPq), Coordenação de Aperfeiçoamento de Pessoal de Nível Superior (CAPES), Fundação de Amparo à Pesquisa do Distrito Federal (FAP-DF) e Universidade de Brasília (UnB).

\section{Referências}

Abreu, A. P. L. (2008) Estudo comparativo da atividade antiinflamatória e antifúngica de extratos de própolis vermelha e verde. Dissertação de mestrado, Universidade Federal do Ceará, Fortaleza, CE, Brasil. http://repositorio.ufc.br/handle/riufc/2185

Adelmann, J. (2005). Própolis: Variabilidade composicional, correlação com a flora e bioatividade antimicrobiana/antioxidante. Dissertação de mestrado, Universidade Federal do Paraná, Curitiba, PR, Brasil. https://www.acervodigital.ufpr.br/handle/1884/1249

Alencar, S. M. (2002). Estudo fitoquímico da origem botânica da própolis e avaliação da composição química de mel de Apis mellifera africanizada de diferentes regiões do Brasil. Tese de doutorado, Universidade Estadual de Campinas, Campinas, SP, Brasil. http://repositorio.unicamp.br/handle/REPOSIP/255828

Alves, C. J. (2018). Microencapsulação de própolis utilizando matrizes proteicas para aplicação como ingrediente funcional em alimentos. Tese de doutorado, Universidade Federal de Pelotas, Pelotas, RS, Brasil. http://www.guaiaca.ufpel.edu.br/handle/prefix/4131

Banzato, T. P. (2018). Atividade anticâncer e anti-inflamatória da própolis vermelha e de seus compostos bioativos: Anticancer and anti-inflammatory activity of red propolis and its bioactive compounds. Tese de doutorado, Universidade Estadual de Campinas, Campinas, SP, Brasil. http://repositorio.unicamp.br/handle/REPOSIP/335361

Bezerra, G. B., Souza, L. D. M., Santos, A. S., Almeida, G. K. M., Souza, M. T. S., Santos, S. L., Camargo, E. A., Lima, B. S., Araújo, A. A. S., Cardoso, J. C., Gomes, S. V. F., Gomes, M. Z., \& Albuquerque, R. L. C., Jr. (2017). Hydroalcoholic extract of Brazilian red propolis exerts protective effects on acetic acid-induced ulcerative colitis in a rodent model. Biomed. Pharmacother, 85, 687-696. 10.1016/j.biopha.2016.11.080

Boeing, T., Mejía, J. A. A., Ccana-Ccapatinta, G. V., Mariott, M., Silva, R. C. M. V. A. F., Souza, P., Mariano, L. N. B., Oliveira, G. R., Rocha, I. M., Costa, G. A., Andrade, S. F., Silva, L. M., \& Bastos, J. K. (2021). The gastroprotective effect of red propolis extract from Northeastern Brazil and the role of its isolated compounds. Journal of Ethnopharmacology, 267, 113623. 10.1016/j.jep.2020.113623

Bueno-Silva, B., Kawamoto, D., Ando-Suguimoto, E. S., Alencar, S. M., Rosalen, P. L., \& Mayer, M. P. (2015). Brazilian red propolis attenuates inflammatory signaling cascade in LPS-activated macrophages. PLoS One, 10(12):e0144954. 10.1371/journal.pone.0144954

Bueno-Silva, B., Kawamoto, D., Ando-Suguimoto, E. S., Casarin, R. C., Alencar, S. M., Rosalen, P. L., \& Mayer, M. P. (2017). Brazilian red propolis effects on peritoneal macrophage activity: nitric oxide, cell viability, pro-inflammatory cytokines and gene expression. J Ethnopharmacol, 207:100-107. 10.1016/j.jep.2017.06.015 
Búfalo, M. C. (2013). Efeito da própolis e de compostos isolados sobre a expressão de receptores, produção de citocinas e atividades fungicida de monócitos humanos. Tese de doutorado, Universidade Bstadual Paulista, Botucatu, https://repositorio.unesp.br/bitstream/handle/11449/104605/bufalo_mc_dr_botfm.pdf?sequence=1

Cavalaro, R. I. (2017). Atividade antioxidante de extratos de própolis verde em sistemas lipídicos emulsionados. Tese de mestrado, Escola Superior de Agricultura "Luiz de Queiroz", Universidade de São Paulo, Piracicabana, SP, Brasil. https://www.researchgate.net/profile/RenataCavalaro/publication/346492928_Antioxidant_activity_of_green_propolis_extracts_in_systems_emulsified_lipids/links/5fc4fe57458515b7978ac762/Antioxid ant-activity-of-green-propolis-extracts-in-systems-emulsified-lipids.pdf

Cavendish, R. L., Santos J. S., Neto R. B., Paixão, A. O., Oliveira, J. V., Araujo, E. D., Berretta e Silva, A., Thomazzi, S. M., Cardoso, J. C., \& Gomes, M. Z. (2015). Antinociceptive and anti-inflammatory effects of Brazilian red propolis extract and formononetin in rodents. J Ethnopharmacol, 173:127-133. 10.1016/j.jep.2015.07.022

Coelho, J., Falcão, S. I., Vale, N., Almeida-Muradian, L. B., \& Vilas-Boas, M. (2017). Phenolic composition and antioxidant activity assessment of southeastern and south Brazilian propolis. Journal of Apicultural Research, 56(1), 21-31, 2017. 10.1080/00218839.2016.1277602.

Dutra, R. P., Nogueira, A. M. C., Marques, R. R. D. O., Costa, M. C. P., \& Ribeiro, M. N. S. (2008). Avaliação farmacognóstica de geoprópolis de Melipona fasciculata Smith da Baixada maranhense, Brasil. Revista Brasileira de Farmacognosia, 18, 557-562. 10.1590/S0102-695X2008000400010

El-Guendouz, S., Aazza, S., Lyoussi, B., Antunes, M. D., Faleiro, M. L., \& Miguel, M. G. Anti-acetylcholinesterase, antidiabetic, anti-inflammatory, antityrosinase and antixanthine oxidase activities of Moroccan propolis. (2016). International J. Food Sci. Technol, 51(8):1762-1773. 10.1111/ijfs.13133

Falcão, S. L. D. M. (2013) Chemical Composition of Portuguese Propolis. Bioactive Properties. Tese de doutorado, Faculdade de Ciências, Universidade do Porto, Portugal. https://www.proquest.com/openview/2dfa8019c2f5172c7b526d924c2bcbdc/1?pq-origsite=gscholar\&cbl=2026366

Falcão, S. I., Calhelha, R. C., Touzani, S., Lyoussi, B., Ferreira, I. C., \& Vilas-Boas, M. (2019). In vitro interactions of moroccan propolis phytochemical's on human tumor cell lines and anti-inflammatory properties. Biomolecules, 9(8):315. 10.3390/biom9080315

Ferreira, J. M. (2019). Própolis e geoprópolis verde do semiárido do brasil: Caracterização química, origem botânica e atividade antioxidante. Dissertação de doutorado, Universidade Federal Rural do Semiárido, Mossoró, RN, Brasil. https://repositorio.ufersa.edu.br/handle/prefix/5182

Ferreira, V. U. (2017). Caracterização química, atividades antioxidante, antileucêmica e antimicrobiana da própolis âmbar sul brasileira. Dissertação de mestrado, Universidade Federal do Pampa, São Gabriel, RS, Brasil. http://bdtd.ibict.br/vufind/Record/UNIP_f5d47a7c4e3e533199c39a4fd151de37

Fianco, A. L. B. (2014). Estudo sobre a atividade antifúngica e antioxidante de extratos de própolis obtidos com CO2 supercrítico. Dissertação de mestrado, Pontifícia Universidade Católica do Rio Grande do Sul, Porto Alegre, RS, Brasil. http://tede2.pucrs.br/tede2/handle/tede/3255

Gargouri, W., Osés, S. M., Fernández-Muiño, M. A., Sancho, M. T., \& Kechaou, N. (2019). Evaluation of bioactive compounds and biological activities of Tunisian propolis. Lwt, 111:328-336. 10.1016/j.1wt.2019.05.044

Hori, J. I., Zamboni, D. S., Carrão, D. B., Goldman, G. H., \& Berretta, A. A. (2013). The inhibition of inflammasome by Brazilian propolis (EPP-AF). Evid. Based Complementary Altern. Med, 2013. 10.1155/2013/418508

Ikegaki, M. (2001). Determinação de qualidade de própolis de Apis mellifera africanizada da região sul do Brasil: avaliação de algumas propriedades fisicoquímicas e biológicas da própolis. Tese de doutorado, Universidade Estadual de Campinas, Campinas, SP, Brasil. http://repositorio.unicamp.br/handle/REPOSIP/255827

Jansen, C. (2015). Própolis: fitoquímicos e atividade antioxidante, antibacteriana e citotóxica. Dissertação de mestrado, Universidade Federal de Pelotas, Pelotas, RS, Brasil. http://guaiaca.ufpel.edu.br/handle/prefix/3881

Jug, M., Končić, M. Z., \& Kosalec, I. (2014). Modulation of antioxidant, chelating and antimicrobial activity of poplar chemo-type propolis by extraction procures. LWT-Food Science and Technology, 57(2), 530-537. 10.1016/j.lwt.2014.02.006

Lima, L. D. C. (2012). Efeito da própolis verde nos componentes angiogênico, inflamatório e fibrogênico em modelo murino de aderência intraperitoneal. Dissertação de mestrado, Universidade Federal de Minas Gerais, Belo Horizonte, MG, Brasil. https://repositorio.ufmg.br/handle/1843/BUBD-9EGMAL

Lungareze, S. (2010). Avaliação histopatológica do efeito de suspensões de própolis na doença periodontal inflamatória induzida em ratos. Dissertação de mestrado, Universidade Federal do Amazonas, Manaus, AM, Brasil. https://tede.ufam.edu.br/handle/tede/3651\#preview-link0

Machado, J. L., Assunção, A. K. M., Silva, M. C. P., Reis, A. S., Costa, G. C., Arruda, D. S., Rocha, B. A., Vaz, M. M. O. L. L., Paes, A M. A., Guerra, R. N. M., Berretta, A. A., \& Nascimento, F. R. F. (2012). Brazilian Green Propolis: Anti-Inflammatory Property by an Immunomodulatory Activity. Evid.-based Complement. Altern. Med, 1-10. 10.1155/2012/157652

Miguel, M. G., Doughmi, O., Aazza, S., Antunes, D., \& Lyoussi, B. (2014). Antioxidant, anti-inflammatory and acetylcholinesterase inhibitory activities of propolis from different regions of Morocco. Food Technol. Biotechnol, 23(1):313-322. 10.1007/s10068-014-0044-1

Moura, S. A. L. D., Negri, G., Salatino, A., Lima, L. D. D. C., Dourado, L. P. A., Mendes, J. B., Andrade, S. P., Ferreira, M. A. N. D., \& Cara, D. C. (2011). Aqueous extract of Brazilian green propolis: primary components, evaluation of inflammation and wound healing by using subcutaneous implanted sponges. Evid. Based Complementary Altern. Med, 2011. 10.1093/ecam/nep112

Naik, D. G., Mujumdar, A. M., \& Vaidya, H. S. (2013). Anti-inflammatory activity of propolis from Maharashtra, India. J. Apic. Res, 52(2):35-43. 10.3896/IBRA.1.52.2.06

Nani, B. D. (2020). Bioprospecção de atividades biológicas e compostos bioativos da própolis orgânica brasileira: Bioprospection of biological activities and bioactive compounds of brazilian organic própolis. Tese de doutorado, Universidade Estadual de Campinas, Piracicaba, SP, Brasil. http://repositorio.unicamp.br/handle/REPOSIP/339348 
Nani, B. D., Sardi, J. D. C. O., Lazarini, J. G., Silva, D. R., Massariolli, A. P., Cunha, T. M., Alencar, S. M., Franchin, M., \& Rosalen, P L. (2019). Antiinflammatory and anti-candida effects of Brazilian organic propolis, a promising source of bioactive molecules and functional food. J. Agric. Food Chem, 68(10):2861-2871. 10.1021/acs.jafc.8b07304

Núñez, D. R., Balboa, N. P., Alvear, M. Z., Ceron, A. N., Abarzua, K. S., \& Vasconcellos, A. C. (2018). Evaluación de la actividad anti-inflamatoria de propóleos chileno sobre cortes histológicos de orejas de ratón. Int. J. Morphol, 36(1):189-193. 10.4067/S0717-95022018000100189

Oliveira, J. V. S. (2020). Estudo dos efeitos neuroprotetores do extrato hidroalcoolico de própolis vermelha em modelos de convulsão induzidos quimicamente em camundongos. Dissertação de mestrado, Universidade Federal do Ceará, Fortaleza, CE, Brasil. http://repositorio.ufc.br/handle/riufc/5604

Pacheco, T. A. R. C. (2001). Determinação das caracteristicas fisico-quimicas e propriedades biologicas das propolis de Apis Mellifera coletadas no Estado de São Paulo. Dissertação de mestrado, Universidade Estadual de Campinas, Campinas, SP, Brasil. http://repositorio.unicamp.br/jspui/handle/REPOSIP/255826

Pandolfo, V. Z. (2014). Caracterização e efeito da variação sazonal da própolis orgânica produzida no sul do Brasil. Dissertação de mestrado, Universidade de São Paulo, Piracicaba, SP, Brasil. https://www.teses.usp.br/teses/disponiveis/11/11141/tde-05012015-154728/en.php

Quintino, R. L., Reis, A. C., Fernandes, C. C., Martins, C. H. G., Colli, A. C., Crotti, A. E. M., Squarisi, I. S., Ribeiro, A. B., Tavares, D. C., \& Miranda, M. L. D. (2020). Brazilian green propolis: chemical composition of essential oil and their in vitro antioxidant, antibacterial and antiproliferative activities. Brazilian Archives of Biology and Technology, 63. 10.1590/1678-4324-2020190408

Rodrigues, V. C., Bueno-Silva, B., \& Moraes, J. (2021). PROSPECÇÃO TECNOLÓGICA DA PRÓPOLIS E SUAS APLICAÇÕES NO CENÁRIO INTERNACIONAL NOS ÚLTIMOS 20 ANOS. RECIMA21-Revista Científica Multidisciplinar-ISSN 2675-6218, 2(7), e27547-e27547. 10.47820/recima21.v2i7.547

Ruiz-Hurtado, P. A., Garduño-Siciliano, L., Dominguez-Verano, P., Martinez-Galero, E., Canales-Martinez, M. M., \& Rodriguez-Monroy, M. A. (2021). Evaluation of the gastroprotective effects of Chihuahua propolis on indomethacin-induced gastric ulcers in mouse. Biomed. Pharmacother, 137:111345. 10.1016/j.biopha.2021.111345

Salas, A. L., Alberto, M. R., Zampini, I. C., Cuello, A. S., Maldonado, L., Ríos, J. L., Schmeda-Hirschmann G., \& Isla, M. I. (2016). Biological activities of polyphenols-enriched propolis from Argentina arid regions. Phytomedicine, 23(1):27-31. 10.1016/j.phymed.2015.11.007

Sartori, G., Pesarico, A. P., Pinton, S., Dobrachinski, F., Roman, S. S., Pauletto, F., Rodrigues, L. C., Jr., \& Prigol, M. (2012). Protective effect of brown Brazilian propolis against acute vaginal lesions caused by herpes simplex virus type 2 in mice: involvement of antioxidant and anti-inflammatory mechanisms. Cell Biochem. Funct, 30(1):1-10. 10.1002/cbf.1810

Silva, J. C. S. (2012). Própolis: teor em fenóis totais e actividades antimicrobiana e inibitória da enzima hialorunidase. Dissertação de mestrado, Instituto Politécnico de Bragança, Bragança, Portugal. https://bibliotecadigital.ipb.pt/handle/10198/8676

Silva, J. C., Rodrigues, S., Feás, X., \& Estevinho, L. M. (2012). Antimicrobial activity, phenolic profile and role in the inflammation of propolis. Food Chem. Toxicol, 50(5):1790-1795. 10.1016/j.fct.2012.02.097

Sousa, J. P. L. M., Pires, L. O., Prudêncio, E. R., Santos, R. F., Sant'Ana, L. D., Ferreira, D. A. S., \& Castro, R. N. (2019). Estudo químico e potencial antimicrobiano da própolis brasileira produzida por diferentes espécies de abelhas. Revista Virtual de Química, 11(5), 1480-1497. 10.21577/19846835.20190103

Tiveron, A. P., Rosalen, P. L., Franchin, M., Lacerda, R. C. C., Bueno-Silva, B., Benso, B., Denny, C., Ikegaki, M., \& Alencar, S. M. (2016) Chemical characterization and antioxidant, antimicrobial, and anti-inflammatory activities of South Brazilian organic propolis. PLoS One, 11(11):e0165588. 10.1371/journal.pone. 0165588

Valenzuela-Barra, G., Castro, C., Figueroa, C., Barriga, A., Silva, X., De Las Heras, B., Hortelano, S., \& Delporte, C. (2015). Anti-inflammatory activity and phenolic profile of propolis from two locations in Región Metropolitana de Santiago, Chile. J Ethnopharmacol, 168:37-44. 10.1016/j.jep.2015.03.050

Vianna, H. R., Soares, C. M. B. M., Tavares, M. S., Teixeira, M. M., \& Silva, A. C. S. (2011). Inflamação na doença renal crônica: papel de citocinas. Brazilian Journal of Nephrology, 33, 351-364. https://www.scielo.br/j/jbn/a/gwSqdy8T56xTkjkzmM7L87y/?format=pdf\&lang=pt

Wang, K., Zhang, J., Ping, S., Ma, Q., Chen, X., Xuan, H., Shi, J., Zhang, C., \& Hu, F. (2014). Anti-inflammatory effects of ethanol extracts of Chinese propolis and buds from poplar (Populus $\times$ canadensis). J Ethnopharmacol, 155(1):300-311. 10.1016/j.jep.2014.05.037

Xuan, H., Yuan, W., Chang, H., Liu, M., \& Hu, F. (2019). Anti-inflammatory effects of Chinese propolis in lipopolysaccharide-stimulated human umbilical vein endothelial cells by suppressing autophagy and MAPK/NF- $\mathrm{BB}$ signaling pathway. Inflammopharmacology, 27(3):561-571. 10.1007/s10787-018-0533-6

Zeggio, A. R. S. (2016). Própolis Catarinense: Influência da Sazonalidade e da Origem Geográfica no Perfil de Metabólitos Secundários. Tese de doutorado, Universidade Federal de Santa Catarina, Florianópolis, SC, Brasil. https://repositorio.ufsc.br/handle/123456789/167683

Zheng, Y., Wu, Y., Chen, X., Jiang, X., Wang, K., \& Hu, F. (2018). Chinese propolis exerts anti-proliferation effects in human melanoma cells by targeting NLRP1 inflammatory pathway, inducing apoptosis, cell cycle arrest, and autophagy. Nutrients, 10(9), 1170. 10.3390/nu10091170 